\title{
Chapter 10 \\ Lessons on Causality from Clinical \\ Encounters with Severely Obese Patients
}

\author{
Kai Brynjar Hagen
}

\subsection{Introduction}

This contribution is about how I came to value and implement the search for a genuinely causal diagnosis in a specific group of patients, the severely obese. When I started to work as a senior consultant at the Regional Centre for Morbid Obesity at Bodø Hospital (RSSO), my background in General Practice (GP) was unusual for the position. The RSSO is a specialist hospital centre assigned to endocrinology within internal medicine, and closely cooperating with surgery. I soon became distressed in my professional role. It seemed to me that the healthcare system in which I was supposed to play my part provided only rather shallow symptomatic diagnosis and therapy. I felt like (one of) " [...] those who are troubled by the disparity between the formal biomedical diagnoses we learned so proudly and the actual human problems that patients bring to us in our offices" (Felitti 2003: 84).

The reason for my distress was that I had decided not to mimic the specialty of endocrinology, but to stick to my GP-approach, conceptualised as whole person care (WPC). This concept has recently been reviewed and described as follows: "a multidimensional, integrated approach; the importance of the therapeutic relationship; acknowledging doctors' humanity; recognising patients' individual personhood; viewing health as more than absence of disease; and employing a range of treatment modalities" (Thomas et al. 2018: 1). The study suggests that "GPs understand WPC to be an approach that considers multiple dimensions of the patient and their context, including biological, psychological, social and possibly spiritual and ecological factors, and addresses these in an integrated fashion that keeps sight of the whole" (Thomas et al. 2018: 8).

I encountered several discrepancies between my whole person approach and the specialist hospital setting. First, the specialist routine was to look at one part of the

\footnotetext{
K. B. Hagen $(\varangle)$

Regional Centre for Morbid Obesity, Bodø, Norway

e-mail: kai.brynjar.hagen@bodo.kommune.no
} 
patient at a time, not the whole person. Second, the obesity centre's approach relied heavily on traditional biomedical practice, reflected in authoritative guidelines for clinical endocrinology and focusing on the somatic comorbidities of obesity (cf. Garvey et al. 2016). There was thus little room for attention to life story and psychosocial conditions. Third, I found that throughout the health system, negative attitudes toward obese people were widespread, assigning them low status and low priority, just as American psychiatrist Hilde Bruch noted almost 80 years ago: "Overeating is looked upon as a moral weakness and self-indulgence. Even physicians may express a sarcastic attitude” (Bruch 1948: 84). Stigmatisation of obese people is paramount, considerably affecting the quality of their care (Phelan et al. 2015; Williams and Annandale 2018).

Were negative attitudes the reason why obese patients with eating disorders were declined from getting help at the Regional Centre for Eating Disorders? Obesity was not listed as a diagnosis in line with anorexia nervosa, and would not be funded as much (less income for the hospital). Consequently, a large group of patients, the obese ones - many of them with a type of background similar to that of their thin counterparts - were simply excluded from this part of the psychiatric department. Referral to trauma treatment was also in many cases declined. The reason that was given was that the patients did not have symptoms of severe psychiatric disease. No, they were not mentally ill, but they had an unbearable feeling of emotional pain inflicted on them. In the manuals of psychiatry diagnosis, there seemed to be no slot for obese patients with emotional pain.

My impression was that healthcare professionals assumed the obese patients to "carry some heavy luggage". These assumptions, however, were neither investigated in depth nor given relevance in the person's records. The healthcare system seemed ignorant of the significance of a causal diagnosis in cases of severe obesity and indifferent towards scientific evidence indicating a potential for improvement when considering the impact of lifetime adversity on health.

Luckily, at RSSO, I am part of a competent interdisciplinary team, including specialist nurses, colleague doctors and a clinical nutritionist as well as surgeons, who have been open to my suggestions to increase the focus on psychosocial factors and adverse life events. In this collaborative environment we have increasingly turned away from a purely biomedical perspective and toward a whole person view on the patients. Discussions within this team have since provided valuable new perspectives on diagnosis, therapy and follow up. We soon realised that the framework for the clinical encounter was one of the things that we could quite easily change. I will here describe the approach with which we are now trying to get closer to causal diagnosis for patients with severe obesity at our centre RSSO, and briefly present three cases from my work there. 


\subsection{A Framework for the Clinical Encounter}

If one is truly to succeed in leading a person to a specific place, one must first and foremost take care to find him where he is and begin there. This is the secret in the entire art of helping. Søren Kierkegaard, 1880

(Kierkegaard et al. 1998)

\subsubsection{The Person in the Role of the Patient - What Are the Goals of Healthcare?}

The role of the patient implies a specific status, framed by legislation, informed by rules and norms, and endowed with rights and duties for the healthcare system as well as for the patient. Every person has unique reasons for entering the role of the patient - which is not always an easy decision. Typically, the outcome of medical intervention depends on the clarification of the reasons for seeking help.

In general practice, learning to identify the patient's goals is mandatory. Consultants seeing patients with obesity in a hospital setting face a similar challenge. Relevant information for understanding the patient's goals might be found in the referral letter. In addition, patients are asked to fill in a form including questions concerning their goals, and how RSSO might help. Reviewing these goals is important at all stages of the further process: at the preparatory seminar, at the clinical encounter and during the follow-up period. Perceptions might change - patients' as well as doctors' - allowing for new perspectives, knowledge and emotional maturing.

Examples of goals may be:

- stopping further weight gain

- losing weight, sometimes specified in kilos or percentage, in some cases aiming at a "normal" Body Mass Index (BMI)

- reducing comorbidities like sleep apnoea, diabetes, hypertension or joint pain

- facilitating improved social participation and avoiding stigmatisation

- improving physical function like hiking in the mountains

- meeting the requirements for a specific job

- enhancing the general quality of life

- being able to spend time with grandchildren.

The patient's expectation of help from RSSO, initially simply being bariatric surgery, may become more differentiated during the course of the consultation process. Analogously, the clinical team's understanding of a patient might improve, enabling them to offer more well-targeted help. 


\subsubsection{A Group Seminar Before the Clinical Encounter: Setting the Stage}

Information about the patient is initially collected from the referral letter and the form. Further preparations for the clinical encounter are made a couple of weeks in advance at a group seminar for 12 patients. At this seminar, members of the clinical team inform about the medical examination, treatment options, the diagnostic approach and therapeutic strategies. They also provide an update on the available knowledge, stress the necessity of avoiding conflicting objectives, and give the patients the opportunity to discuss with them. During the seminar, the patients and the team members become more familiar with each other's attitudes and priorities.

The information the team conveys at the preparatory meeting includes the following points:

- Everyday physical activity on a sustainable level is recommendable, but physical training normally cannot compensate for too high energy intake.

- Nutrition issues are discussed, especially the discrepancy between cognitive knowledge and actual practice, which means that emotions often play a major part in determining eating behaviour. A better mental condition may make it easier to practice nutritional knowledge.

- The significance of bio-rhythms is outlined, especially the fact that regular circadian rhythm and meal rhythm is physiologically preferable.

- The emerging scientific understanding of the microbiota functions is mentioned, and also the epigenetic principles.

- We acknowledge that people with obesity might be exposed to different sorts of bullying and violations of their integrity, which makes active self-defence strategies important.

- Harmful stress is probably one of the most important causal factors for becoming obese, linked to a variety of adverse life events. Adverse events can lead to mental and physiological overactivation and painful feelings, which to some extent can be relieved by overeating, called emotional eating. Understanding these mechanisms should replace moralisation. I give an example from my own experience of stressful situations during night duties: chocolate with marzipan makes me more relaxed. A brief stress-relief very much needed at the time, this effect would not be achieved with a green salad. A stressful situation for a couple of hours is one thing, chronic never-ending stress is something quite different-perhaps I would have to 'take' chocolate continuously for relief? That might be one possible mechanism for the onset of overweight. A number of other possible coping mechanisms are known, for instance drug abuse, self harming and anorexia. In my opinion, the emotional pain caused by traumatic stress is not a mental illness, rather a normal reaction to an abnormal strain.

We present the patients with our goal: the dialogue between patient and doctor is successful if it brings an insight that neither of them could have achieved alone. The dialogue aims at a deeper understanding of the patient's life history and the current 
situation to enhance the validity of the diagnosis, and thus pave the way for effective therapy. Patients are encouraged to be prepared for a rather thorough and comprehensive review of their life history, but of course only as far as it feels natural; no one will be subjected to pressure. We will ask certain questions, such as, for example: Which life events could have contributed to the onset of undesirable weight gain? How is the current situation maintained? In some cases, one single identifiable cause leads to a person becoming overweight; other cases are unclear and complicated. We underline the importance of a whole person view, the uniqueness of every individual and the complexity of causal factors, rendering comparisons between patients invalid. We explain that the weight graph will be plotted on a timeline to look for possible correlations with life events.

\subsubsection{The Consultant's Understanding in Advance of the Clinical Encounter}

In advance of the clinical encounter, I take a few minutes to review the available information about the patient, filling data in the template for the medical record. This template includes not only biomedical data, but also an extended part for the life story, especially psychosocial conditions, as well as data for the weight graph. Sources of information are the referral letter, the patient's preceding, written answers in a form, and results from blood tests or other supplementary tests. Sometimes I also make notes concerning my impressions during the group seminar.

I reflect upon what the patient's everyday life may be like, where he or she actually is. In a meta perspective, as a kind of self observation, I try to be conscious of my own position, my background, experience, personality, current situation and communicative ability, since all this will influence the dialogue, the dynamic interaction, and consequently also the picture of the patient's life. Hypothetically, another doctor in my place would probably have come to slightly different conclusions. In some cases patients came to me for follow-up, and it became quite clear that the description of the patient's life story did look quite different in my view compared to the written record from the original examination. An example of this might be the patient who, after bariatric surgery some years ago and initial weight loss, came to me as he now had the same weight as the maximum weight presurgery. In my view, this was because his traumatic life story had not been addressed, understood and taken into account. As healthcare professionals, we all have different colored glasses through which we see the patient. These aspects of clinical communication have not been part of my training from medical school, but evolved through the years of clinical practice, and heavily inspired by dispositionalism. Young doctors have had training in patient-doctor communication, but it seems to me that the aspect of being part of the causal profile of the patient has not been addressed. 


\subsubsection{The Clinical Encounter}

At the start of the clinical encounter, I ask whether the patient feels comfortable, which is a way to pay respect to her or his current situation, and also to find a good starting point for the dialogue. I regularly ask: "Did you sleep well last night? How was your journey?" In some aircrafts on regional flights, severely obese people are denied access because the seats are too narrow. In addition, the winter in Northern Norway can make any journey challenging. I also used to ask: "Does it feel stressful for you to come here?" Often, the patients express mixed feelings, being happy for being admitted to the clinic, but feeling uncomfortable about addressing their obesity. The patient may recently have been ill or injured, or is worried about children back home, among other things.

I go on to inform the patient about my way of working: that I have a template with the topical themes, that I will type part of what is said as we go along so that correct expression can be preserved, that we will review blood analysis results and medication, that we will carry out a brief somatic examination, and that together, we will assess further follow-up options.

I ask the patient about allergies, surgery, pregnancies/births, diseases, known risk factors, heredity, social situation (family, education, work, social participation), natural functions (circadian rhythm, sleep duration/quality, urination, stools, menstruation), physical activity, dental status (does he or she suffer from odontofobia?), use of tobacco and alcohol. Sexual function is not routinely addressed, unless the patient takes the initiative.

\subsubsection{As a Child, Did You Feel Safe at Home?}

The main focus of the clinical encounter, however, is the life story. I usually ask the patient: "As a child, did you feel safe at home?" This is one of the themes that can open the discussion for stories of violence, drug abuse, parental mental illness, incest, traumatic loss of a person close to them, and so on. I became aware that there are many forms of violence. As Norwegian writer Yngve Hammerlin - a man with severe childhood violence experiences - has pointed out, violence is often not adequately understood by doctors. From the point of view of those who have experienced violence, the professional's response can thus signal desperate simplification and reductionism. Hammerlin suggests that the attitudes of healthcare professionals need to reflect a deeper understanding of the many types and consequences of violence (Hammerlin 2014). The wounds of an unsafe childhood are also described by Swedish authors, Josefsson and Linge (2011).

I explicitly ask about social participation with children of the same age, as well as physical activities, well-being at school and how school subjects were managed. At this point, there are often heart-breaking stories about bullying during many years at school, and of social isolation. From early childhood, via pre-school, 
adolescence, elementary school, high school, and into young adulthood, many facets form a picture of the person's development, of adverse and supportive events, of weaknesses and strengths, all in a whole person view. Relations to family members, partners or spouse, as well as certain social relations, are important determinants for life quality. Some patients find themselves in a marriage with a psychopathic person, only, after divorce, to be persecuted by the same person. Also, predators abusing children sexually are very seldom brought to justice, based on what patients tell me. Some report that their childhood predator still lives in the local community, and there is always a risk of accidentally meeting him, which provokes stress and fear.

We try to compare variations of the weight graph with changes in the psychosocial situation. Sometimes there seems to be a causal relation between adverse events, or stressful periods, and weight gain. Other forms of emotional regulation like selfharming, drug abuse or anorexia life style can have occurred in certain periods of life. A minority of the patients have had psychiatric therapy, which, however, rarely seems to have addressed adverse life events. Psychiatric healthcare is comprehensive and includes a large variety of diagnostic and therapeutic methods. It seems to me that it has been a widespread perception that trauma in the patient's history should not be mentioned, due to an estimated risk of re-traumatising, whereas other institutions practice methods with basic trauma understanding. One example of the latter is the Viken Senter in Northern Norway (www.vikensenter.no).

During the clinical encounter it sometimes feels like the dialogue exists as an independent unit, giving insight neither patient nor doctor could have acquired on their own, based on communication with mutual respect and engagement, and equally shared contributions.

Before ending the consultation, test results are carefully explained, medication is considered, somatic screening is done, we summarise and make a plan for further follow-up.

\subsubsection{The Consultant's and Patient's Understanding After the Clinical Encounter}

The patient's nutrition is thoroughly evaluated by the clinical nutritionist or a specialist nurse, either before or after the clinical encounter. In case bariatric surgery is an aim or an option, the surgeon will also see the patient. Later on, when the reports on nutrition and surgery assessment are complete, I summarise the conclusions in the record which is sent to the local hospital and the patient's GP, electronically available for the patient, and sometimes also sent as a referral to a rehabilitation centre or a psychiatric ward where basic understanding of adverse life events is practiced. The clinical team might discuss the case.

After 2 days in the clinic, patients have a normal follow-up period of 6 months during which they are supposed to have a phone consultation with one of the specialist nurses or the clinical nutritionist every 2 weeks, with the goal of modifying 
lifestyle to lose weight, often discussing psychosocial conditions. In some cases, additional consultations at the clinic are necessary. Further treatment can be more conservative or supported by bariatric surgery. The post-surgery programme has been extended to 5 years.

A locally based coordinated team can be beneficial during a comprehensive follow-up, involving the patient, the GP, and other professionals according to the needs of the individual patient. If needed, RSSO can take part in a meeting with the local coordinating team by phone or by video/Skype.

The post-encounter period gives a deeper understanding of the individual patient as well as the causal factors involved. Symptomatic diagnosis and therapy might be useful for a limited period of time, but our ambition is always the causal diagnosis and therapy.

In order to demonstrate how this intention might be achieved, three vignettes will be presented. The clinical encounter can be enriched and provide new insights in light of biographical information focusing on relational and social issues during the actual patient's lifetime from childhood through adolescence to the present state. The three anonymised persons whose stories unfold in the following have consented to the publication of their accounts in this book.

\subsection{Case Stories}

\subsubsection{Olav Olsen, a Severely Obese Man}

When enrolled and examined at the RSSO, Olav Olsen, 45 years old, weighs $123 \mathrm{~kg}$, his Body Mass Index (BMI) is $40.6 \mathrm{~kg} / \mathrm{m}^{2}$ and the waist circumference is $132 \mathrm{~cm}$. He relates that his maximum weight has been $126 \mathrm{~kg}$, and that various attempts to reduce weight have always been succeeded by weight gain.

Olav has been diagnosed with gastrointestinal reflux, oesophagitis, high blood pressure, sleep apnoea, type II diabetes (insulin-regulated), bronchial asthma since childhood, Mb. Bechterew since age 21, osteopenia, allergy and eczema. Additionally, liver enzymes and blood glucose measures are above the upper norm, and he suffers from generalised muscular pain. Cognitive psychotherapy has recently ameliorated his previously incapacitating social anxiety. He uses on regular basis a wide range of medications. With regard to possible heredity, type II diabetes and coronary heart disease (father) in addition to asthma and hypertension (both parents) should be mentioned.

Olav is single, has received a disability pension since age 31 and lives with his parents in a rural area. Meals are typically prepared by his mother and characterised by being irregular and high in carbohydrates. He himself describes his eating habits as "always eating too much and never having a feeling of satiety".

Olav relates that his childhood home was a safe place until he was 9 years old. From then on and until age 15 years, he was sexually abused by some uncles and 
cousins. However, he started being overweight already as a pre-schooler, and physical activities with his peers gradually decreased until he was in 6th grade. He was not exposed to bullying at school and learned the school subjects reasonably well until the age of 12 , when he became anxious and concentration problems arose. 14 years old, he was so afraid of speaking up in class that he often hid in the lavatory to avoid such exposures. At 16 he had become clearly obese $(91 \mathrm{~kg})$. He did not enter secondary school due to significant anxiety.

When 24 years old, Olav's GP referred him to an outpatient psychiatric clinic where he received considerable help, and by age 27 he felt ready to report his sexual abusers to the police. Six of his uncles and cousins were taken into custody. The legal process lasted for 4 years, but without a criminal charge due to insufficient evidence. Olav received, however, criminal injuries compensation. Olav's case was reported in all media, which caused him considerable distress. He rapidly gained weight during these years, and at age 28 his weight was $103 \mathrm{~kg}$.

In accordance with this highly informative and detailed first encounter, the following measures concerning Olav's medical demands and further treatment were proposed: an interdisciplinary follow-up including psychosocial support, improved co-morbidity disease management, assistance for lifestyle changes via frequent telephone conversations and, having implemented lifestyle changes leading to $10 \%$ weight loss, possibly bariatric surgery.

\subsubsection{Alma Almas, a Severely Obese Woman}

Alma is 26 years old when she comes to the clinical encounter. Her weight is $127,5 \mathrm{~kg}$, her BMI $41.6 \mathrm{~kg} / \mathrm{m}^{2}$, and her waist circumference $129 \mathrm{~cm}$. Vitamin D deficiency is found by the blood tests. Alma has been diagnosed with polycystic ovary syndrome, a condition resulting in multifocal pains and bleeding related to the menstrual cycle. She reports that her father is obese as well, and that he has been diagnosed with diabetes.

Alma drinks only minimal amounts of alcoholic beverages and doesn't smoke but uses snuff (nicotine). She has lived with her boyfriend for the last 3 years but has no children. Her level of daily activity is high: housework and dog-walking for $45 \mathrm{~min}$ twice a day and exercising $75 \mathrm{~min}$ three times a week at a fitness centre. She has worked as an assistant caretaker for mentally impaired patients since she was 21 years old. Except for the previous year, she has worked at night, resulting in frequent change of her circadian rhythm, causing stress and insomnia, leading to the use of sleeping pills.

Alma reports a lack of care during childhood. Her mother had been raped as a child and has been suffering from fibromyalgia as an adult. Her 2 years younger sister had craved much of her parent's attention due to sleeping problems until age three, and as a result of this they were often exhausted. Alma's family, living in a rural area, had poor economic resources, implying, among other things, impaired 
nutrition for all family members. Her father, working in a grocery store, would bring home expired food for free. Sweets were locked up.

The onset of Alma being overweight came when she was 8 years old. Although being one of only five pupils in her school class, her dyslexia was undiagnosed until she was 11 years old. As she had exercise-induced asthma (also undiagnosed for a long time), her ability to participate in physical activities was limited. Her social life as a child was poor, partly because of her habit to withdraw from the others and preference for being by herself.

Alma recalls that she at age 13, when spending her holidays at her paternal grandmother's, experienced a severe food restriction, leaving her constantly hungry for 4 weeks. This was a relational trauma because of the pressure she was exposed to, as well as a sort of somatic trauma related to starving. Later she learned that her grandmother had previously been hospitalised due to anorexia. When reporting this experience, Alma is visibly emotional.

She is almost amnestic for the time from age 13 to 18 years of age. She assumes that she must have suffered from severe depression. During these years she consumed large quantities of sweets and gained weight continuously. When 18 years old, she left home to attend a college in a larger town while also working part-time in a grocery shop. One year later, she experienced severe symptoms of burnout and could neither work nor study for 1 year. Frequent psychotherapeutic consultations over 6 months were helpful.

At 19 she had a break-up with her then boyfriend. At 22 she was assaulted on her way home from work by one of the mentally impaired patients; he had a knife, but she managed to escape.

Alma was informed about different treatment options, and has had a quite normal follow-up at the RSSO, consisting of mainly telephone consultations with the specialist nurse and no specific psychiatric therapy.

\subsubsection{Ebba Eskil, a Severely Obese and Depressed Woman}

At the time of medical examination at the RSSO, Ebba is 46 years old. Her weight is $106 \mathrm{~kg}$, her BMI is $39 \mathrm{~kg} / \mathrm{m}^{2}$, her waist circumference is $131 \mathrm{~cm}$. She has been diagnosed with type II diabetes at age 27 , and her blood glucose is not well regulated. In addition, tests indicate vitamin D deficiency. She suffers from sleep apnoea and was treated with a positive airway pressure ventilator; continuous positive airway pressure (the positive air pressure made by a fan reaches the throat and keeps the airways open through the night). Furthermore, she has chronic lower back pain, neuropathic pain in both legs, oesophagitis and frozen shoulder. She was diagnosed with depression at age 42 and takes antidepressants. Her diet is high in carbohydrate and fat, with emotional eating and sometimes losing control. Previously a cleaner, she had been unable to work the last 4 years due to myalgia, diabetes and obsessivecompulsive disorder (OCD), and is receiving disability benefits. 
She had surgery for an extrauterine pregnancy at age 25, gave birth to her first child at age 27 (vaginally), and to her second and third child by means of Caesarean sections at age 29 and 35 years. She lives together with her husband and three adolescent children.

As a child, she always felt unsafe at home. Her parents often had terrifying conflicts. Her father once cut a picture on the wall to pieces with a knife. She had one older and one younger sister; the children normally had to find food without help from either parent. Her relationship with her mother was especially difficult. The mother worked as a cleaner and forced her daughter to assist her at work, thereby isolating her socially from girls her own age. Her mother was addicted to gambling, frequently losing money. Her parents did not contribute to activities for children and parents at school. In addition, her dyslexia made for a difficult time at school. In the end, she had to take responsibility for her parents, being deprived of her own childhood.

Until she was 15-16 years of age, her body weight was normal. At 16, she moved out from home into a dorm. She rapidly gained weight, reaching a maximum of $126 \mathrm{~kg}$. Due to increasing OCD symptoms she was referred to an outpatient psychiatric department.

A plan for care and follow-up was made, with focus on mental health support, improving nutrition and diabetes management, eventually bariatric surgery.

\title{
10.4 Where Do We Go from Here?
}

\author{
Her hair reminds me of a warm safe place \\ Where as a child I'd hide \\ And pray for the thunder \\ And the rain \\ To quietly pass me by \\ Lyrics from “Sweet Child o' Mine” (Guns N' Roses)
}

For me, the clinical encounters have been a most valuable source of knowledge. In the dialogues with the patients, new insights have been opened concerning the causal factors for obesity. It has been a truly educational journey into the unique history of each individual.

As a child, did you feel safe? From January 2013 to July 2019, this question has been answered in 755 clinical encounters. The answers have revealed crucial adverse life events, each one unique, outrageous and challenging. The keywords are trauma, loss of a related person, sexual assault, deprivation of care and safety, exposure to violence and bullying. It seems especially harmful to be treated badly by one's mother. One patient told me that her mother said she wanted just three children, but this daughter was her fourth child, and she was treated accordingly.

I have come to reflect on some uncomfortable questions. How many people have been exposed to severe trauma or other adverse life events in childhood? In how many cases has trauma been succeeded by the onset of overweight, then bullying, 
social withdrawal, increasing weight and emerging comorbidities? How many other sequelae of trauma are prevalent?

Beyond the individuals, the clinical encounters have also provoked fundamental questions concerning health, disease and healthcare. How much injustice has been committed? How many people have known but not interfered? How many obese people have been economically exploited by the providers of the countless, aggressively promoted slimming products, symptomatic treatments and dubious surgery? What is the total amount of damage to the individual and to society? Are the national healthcare systems meeting obese persons in an adequate way?

Where do we go from here? In the next sections, I briefly outline the scientific evidence and make some suggestions for changes in clinical practice.

\title{
10.4.1 "What the Hell Is Going on Here?"
}

\author{
Yes, 'n' how many times can a man turn his head \\ Pretending he just doesn't see? \\ Lyrics from 'Blowin' in the Wind' (Bob Dylan)
}

Scientific evidence has at least since 1940 pointed to the importance of life stories for health and deepened our understanding of this causal relationship - although apparently without much impact on healthcare systems or clinical practice yet. Here are some episodes from medical science to illustrate the evidence.

In 1940, psychiatrist Hilde Bruch quoted Lichtwitz (1923) as observing rapidly developing obesity in women who had been under severe mental stress during and after the 1914-1918 war. However, it seems that this observation was not taken into the internal medical discussions on causality in the 1920's, when quite a lot of medical research was done on the causal factors of obesity. Life history was ignored, while biochemical and pathophysiological evidence known at the time seem to be thoroughly investigated in search for causality. Focus was on metabolic, endocrinologic and biochemical conditions. A salient conclusion was that obesity is not possible without malfunction of the central metabolic regulation (Bernhardt 1929). ${ }^{1}$

On the basis of her own work, Bruch described a home environment that did not offer adequate emotional security, and where food had gained an exaggerated importance; charged with a high emotional value, it represented love, security and satisfaction. The child may opt for the pleasures of food if it does not get the pleasure of love from its parents (Bruch and Touraine 1940). In 1949, psychiatrist

\footnotetext{
${ }^{1}$ This might be the roots of endocrinology being the branch of medicine responsible for obesity during the last century, as established in guidelines. The diagnosis of severe obesity in a traditional biomedical sense does not focus on life story, psychosocial conditions or adverse life events; however, somatic comorbidities are highlighted. An example of this is the authoritative American Association of Clinical Endocrinologists and American College of Endocrinology Comprehensive Clinical Practice Guidelines for Medical care of Patients with Obesity (Garvey et al. 2016).
} 


\title{
H. J. Shorvon and GP John S. Richardson at St Thomas' Hospital in Cambridge, UK, described some important clinical observations:
}

\begin{abstract}
The investigation first arose when it was observed that some obese patients who failed to respond satisfactorily to the usual methods of treatment dated their obesity and also some psychoneurotic symptoms to a specific incident that might well have inflicted psychological trauma. We found that too little attention had been paid to the emotional factors in the first instance, and the patients had been treated on an organic basis for long periods. We do not claim that the treatment pursued with this group is primarily aimed at reducing weight, but we have used it to alleviate the associated mental distress and have found that patients often show a parallel reduction of weight and become more amenable to accepted methods of treatment of obesity. (Shorvon and Richardson 1949: 951)
\end{abstract}

In the 1980s, Vincent J. Felitti, an internist who founded the Department of Preventive Medicine at Kaiser Permanente in San Diego, made similar observations. He witnessed a paradoxical tendency for patients who had successfully lost weight in his ward to not participate in the follow-ups. He ended up asking himself: "What the hell is going on here?" (Kirkengen 2019). Felitti decided to ask these patients about their background, and he found that each of them had experienced considerable adversity (ibid.). In the "Adverse Childhood Experiences Study" (ACE-Study) Felitti and his colleagues later found a dose-response relationship between childhood trauma and obesity, as well as a range of other diseases (Felitti et al. 1998). More recently, a relationship in line with the ACE-Study was found in a Norwegian setting (Tomasdottir et al. 2015). A significant relationship between exposure to violence in adolescence and being overweight has also been demonstrated (Stensland et al. 2015). The relationship has been confirmed in recent metaanalyses (Danese and Tan 2014; Wang et al. 2015; Hemmingsson et al. 2014). A chronological relationship between adverse life events and the onset of obesity has been shown in a study by Lynch et al. (2018).

It is fairly well-established that emotional eating can be caused by trauma, depression and post-traumatic stress disorder (PTSD) (Talbot et al. 2013). The observations of the role of mental stress in Litchwitz (1923), and Bernhardt's (1929) focus on changes in brain physiology, both point to modern scientific theories of allostatic overload as a possible mechanism for the connection between trauma and obesity. Allostasis is "the process by which a state of internal, physiological equilibrium is maintained by an organism in response to actual or perceived environmental and psychological stressors."2 Allostatic load involves psychological, neurological, endocrinological and immunological processes to cope with mental or physical challenges. Overload might result in dysregulation, and possibly disease (McEwen 2012).

Back at the RSSO, I asked myself why this scientific evidence has not been implemented in clinical practice. Why has accumulated knowledge from seven or eight decades not yet been acknowledged in healthcare? Even the modern, authoritative medical resource UpToDate does not mention very much about psychological

\footnotetext{
${ }^{2}$ Merriam-Webster online dictionary, entry on "allostasis". https://www.merriam-webster.com/ dictionary/allostasis [accessed 9 June 2019].
} 
causes apart from winter depression (Perreault 2019). Typically, aetiology is outlined, both in childhood and adulthood, practically without any reference to psychosocial conditions.

\subsubsection{Is This How the System Works?}

I want you to panic.

Greta Thunberg, environmental activist

What lies under the surface of symptoms? What is under the surface of healthcare systems? Are our healthcare systems built on shallow interpretations of symptoms, failing to understand and respect the true causes of disease? Can this unpleasant question generally, or only partially, be answered with "yes"? In that case, a fundamental change of concepts would be urgent, a new paradigm needed. I will now present my subjective impression of some parts of healthcare, based on decades of clinical experience in a Norwegian setting.

Experiences that exceed a person's coping capacity result in some kind of damage to health because they provoke harmful stress, emotional pain and pathophysiological consequences. Furthermore, they affect the whole person as well as her or his interactions within ecosystems he or she is involved in, including epigenetic effects.

Every living creature will try to get rid of, regulate or at least soften any form of unpleasant, harmful condition or imbalance. Overeating is only one of many possible ways to achieve relief. We still don't know why certain coping strategies are chosen instead of other alternatives, such as self-harming, drug abuse, and so on. These desperate measures, meant for regulation, can result in a variety of symptoms, some obvious, some hidden and complex.

The obvious symptoms are easily picked up in the healthcare system, interpreted according to rigid professional guidelines and traditions, then categorised in algorithm-based diagnostic systems. One example is the Diagnostic and Statistical Manual of Mental Disorders (DSM), an American concept generally adopted by Western countries. The DSM is overwhelmingly comprehensive, barely leaving any human being without a diagnosis, and it is widely used as a basis for drug manufacturing, financing within healthcare systems, for building up specific departments in healthcare systems and, what is worst: for putting persons into stigmatising categories, often randomly, as their symptoms may fit into many different diagnoses. As a person, you are defined in the light of your diagnosis, and you can be stuck in that narrow prison cell for a long time, deprived of empowerment, deprived of unfolding on your own terms, forced into the world of white coat guidelines.

Generally, it is hard to get rid of a diagnosis once established, regardless of how wrong it might have been. In some aspects, the symptomatic diagnosis is useful, but not as a replacement for the causal diagnosis. A patient with a broken leg who has symptoms like pain and not being able to walk is grateful for symptomatic therapy 
with analgesic drugs and a wheelchair, but in the long run he will be even more grateful for causal therapy: orthopaedic surgery. Persons with obesity are generally denied such causal diagnosis, and consequently, deprived of causal therapy. The utterly shallow diagnoses keep people chained in a position with impaired quality of life, exploited financially by a number of agencies, including health "care". Causality means not only considering the top of the iceberg, not being stuck in superficial symptoms, but to rather take a look beneath the surface, approaching a deeper understanding.

For the last 80 years or more, the importance of a person's life story has been documented. This is where the roots of poor health may often be found, which is a basic premise for cure and enhanced quality of life. Let the patient's life story always be part of the clinical encounter.

We should panic for

- all the people with traumas not receiving adequate help

- the amount of avoidable childhood trauma that our communities fail to prevent

- the healthcare resources being wasted on ineffective or harmful treatment

- the fact that valid knowledge is not implemented in clinical practice

- the fact that our civilisation still stigmatises a large part of the population, meeting them with sarcasm, ruining their self-esteem.

\subsection{Outlook}

Starting work in the traditional biomedical environment in hospital, I felt the same as expressed by Shorvon and Richardson (1949: 951), "that too little attention had been paid to the emotional factors in the first instance, and the patients had been treated on an organic basis for long periods." This situation may have been caused by the medical funding system that rewards quantity but ignores quality of care. Reasons for this situation may also include the view on causality on which our medical system is based. This view - characterised by lack of attention to the individual and to the interacting factors in the individual's life - also suits business interests too well and contributes to diagnostic and therapeutic restraints. The present volume makes a wonderful contribution to addressing this societal problem.

When, at RSSO, we decided to give much more attention to each patient's life story, setting aside sufficient time for the dialogue, this was a sign of respect, a courtesy to the patients - and I also hoped to create room for new insights and causal diagnosis. The responses from the patients have been positive. They have appreciated being given more time, being listened to, having an opportunity to get rid of shame and to develop deeper insight into how their condition and life story might be interwoven. Many have expressed thankfulness and have been willing to contribute to research. This suits my feeling that we do in fact generate insights in the dialogues. 
I have thus decided to try to contribute to research on the severely obese patients from Northern Norway. ${ }^{3}$ On 18 October 2018, Martine B Aaseng (patient), professor Linn Getz and the chief executive officer of the Health Administration for Northern Norway (Helse Nord RHF), Lars Vorland, gave an interview on Norwegian television. Getz said that knowledge about the importance of life history is now so well founded that it is time it gets implemented into clinical practice. Vorland responded quite honestly that he had not been aware of this. ${ }^{4}$

As my profession is medical practice, not research, the apparent deficits in diagnosis and treatment of the severely obese were what alerted me to the failure of a system that I had become a part of. But my encounters with researchers Anna Luise Kirkengen, Linn Getz and Rani Lill Anjum helped give me a sound theoretical platform that matches my clinical experience. Four decades after medical school, their work undoubtedly renewed and expanded the basic platform on which my clinical practice is built. This has also had a major impact on my work as GP and at the Norwegian Work and Welfare Authority. It feels right, in every aspect of clinical medicine, to acknowledge patients' life stories as essential parts of the causal diagnosis that medicine should always strive to achieve. In the clear light of dispositionalism, elaborated in this book, it is now time for changing the game, for a new paradigm in medicine to be accepted and implemented in care, in order to give patients the help they deserve. ${ }^{5}$

\section{References and Further Readings}

Bernhardt H (1929) Kapitel I: Zum Problem der Fettleibigkeit. In: Czerny A (ed) Ergebnisse der Inneren Medizin und Kinderheilkunde. Springer, Berlin, pp 1-55

Brewerton TD (2017) Food addiction as a proxy for eating disorder and obesity severity, trauma history, PTSD symptoms, and comorbidity. Eat Weight Disord 22:241-247

Bruch H (1948) Psychological aspects of obesity. J Urban Health 24:73-86

Bruch H, Touraine G (1940) Obesity in childhood; family frame of these children. Psychosom Med 2:141

Danese A, Tan M (2014) Childhood maltreatment and obesity: systematic review and metaanalysis. Mol Psychiat 19:544-554

Felitti VJ (2003) Review of: inscribed bodies: health impact of childhood sexual abuse by Anna Luise Kirkengen. Kluwer Academic, Boston, 2001. Permanente J 7:84

Felitti VJ, Anda RF, Nordenberg D, Williamson DF, Spitz AM, Edwards V et al (1998) Relationship of childhood abuse and household dysfunction to many of the leading causes of death in adults. The Adverse Childhood Experiences (ACE) Study. Am J Prev Med 14:245-258

\footnotetext{
${ }^{3}$ As a board member in the Norwegian Association for the Study of Obesity, I initiated a national conference in Bodø, Norway, in October 2018. Connections between adverse life events and obesity were highlighted in Martine B Aaseng's (patient) testimony and in scientific contributions by researchers Anna Luise Kirkengen, Linn Getz, Rani Lill Anjum, Trine Tetlie Eik-Nes and others.

${ }^{4}$ https://tv.nrk.no/serie/dagsrevyen/201810/NNFA19101818/avspiller; minutes 20.58-23.00 [accessed 9 June 2019].

${ }^{5}$ I would like to thank Kristin Hagen for all her helpful feedback on language, structure and presentation of this chapter.
} 
Garvey WT, Mechanick JI, Brett EM et al (2016) American Association of Clinical Endocrinologists and American College of Endocrinology comprehensive clinical practice guidelines for medical care of patients with obesity. Endocr Pract 22:1-203. https://doi.org/10.4158/EP161365

Hammerlin Y (2014) Når fysisk og psykisk vold blir en reduksjonisme. Tidsskrift for Den norske legeforening 134:1812. https://doi.org/10.4045/tidsskr.14.0939

Hemmingsson E, Johansson K, Reynisdottir S (2014) Effects of childhood abuse on adult obesity: a systematic review and meta-analysis. Obes Rev 15:882-893

Josefsson D, Linge E (2011) Den mörka hemligheten, att lämna det förflutna bakom sig och skapa ett tryggare liv. Natur \& Kultur Akademisk, Stockholm

Kierkegaard S, Hong HV, Hong EH (1998) The point of view. Kierkegaard's writings, vol 22. Princeton University Press (first published 1848-49/1859)

Kirkengen AL (2019) En syk kilde [Essay on «The deepest well» by Nadine Bruke Harris]. Tidsskrift for den norske legeforening. https://doi.org/10.4045/tidsskr.18.0622

Lichtwitz L (1923) Über die beziehungen der fettsucht zu psyche und nervensystem. Klin Wochenschr 2:1255-1257. https://doi.org/10.1007/BF01709672

Lynch AI, McGowan E, Zalesin KC (2018) "Take me through the history of your weight": using qualitative interviews to create personalized weight trajectories to understand the development of obesity in patients preparing for bariatric surgery. J Acad Nutr Diet 118:1644-1654

McEwen BS (2012) Brain on stress: how the social environment gets under the skin. Proc Natl Acad Sci U S A 109(Suppl 2):17180-17185

Perreault L (2019) Obesity in adults: etiology and risk factors. UpToDate. www.uptodate.com

Phelan SM, Burgess DJ, Yeazel MW, Hellerstedt WL, Griffin JM, van Ryn M (2015) Impact of weight bias and stigma on quality of care and outcomes for patients with obesity. Obes Rev 16:319-326

Shorvon HJ, Richardson JS (1949) Sudden obesity and psychological trauma. Br Med J 2:951-956

Stensland SO, Thoresen S, Wentzel-Larsen T, Dyb G (2015) Interpersonal violence and overweight in adolescents: the HUNT study. Scand J Public Health 43:18-26

Talbot LS, Maguen S, Epel ES, Metzler TJ, Neylan TC (2013) Posttraumatic stress disorder is associated with emotional eating. J Trauma Stress 26:521-525

Thomas H, Mitchell G, Rich J, Best M (2018) Definition of whole person care in general practice in the English language literature: a systematic review. BMJ Open. https://doi.org/10.1136/ bmjopen-2018-023758

Tomasdottir MO, Sigurdsson JA, Petursson H, Kirkengen AL, Krokstad S, McEwen B et al (2015) Self reported childhood difficulties, adult multimorbidity and allostatic load. A cross-sectional analysis of the Norwegian HUNT study. PLoS One 10(6):e0130591

Wang Y, Wu B, Yang H, Song X (2015) The effect of childhood abuse on the risk of adult obesity. Ann Clin Psychiat 27:175-184

Williams O, Annandale E (2018) Obesity, stigma and reflexive embodiment: feeling the 'weight' of expectation. Health, London. https://doi.org/10.1177/1363459318812007

Open Access This chapter is licensed under the terms of the Creative Commons Attribution 4.0 International License (http://creativecommons.org/licenses/by/4.0/), which permits use, sharing, adaptation, distribution and reproduction in any medium or format, as long as you give appropriate credit to the original author(s) and the source, provide a link to the Creative Commons license and indicate if changes were made.

The images or other third party material in this chapter are included in the chapter's Creative Commons license, unless indicated otherwise in a credit line to the material. If material is not included in the chapter's Creative Commons license and your intended use is not permitted by statutory regulation or exceeds the permitted use, you will need to obtain permission directly from the copyright holder.

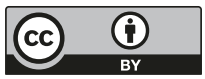

